\title{
Consumo de alcohol y mortalidad por cardiopatía isquémica en Rusia
}

\section{Alcohol consumption and ischemic heart disease mortality in Russia}

\author{
| YURY E. RAZVODOVSKY
}
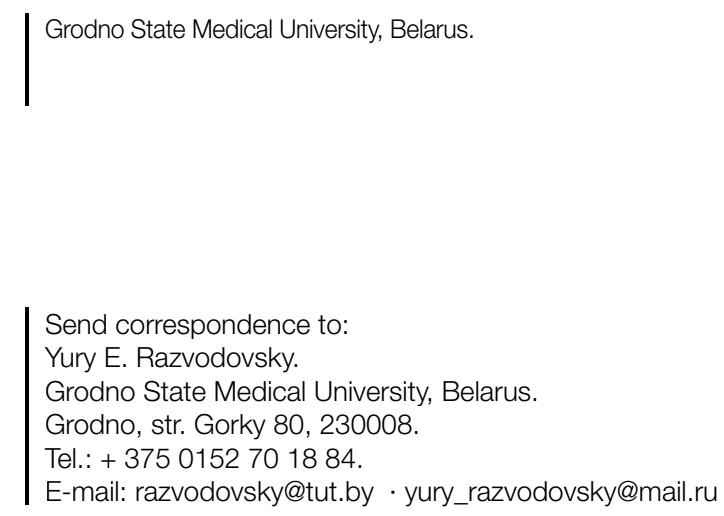

\section{Resumen}

Se ha insistido reiteradamente en que el alcohol proporciona la explicación más plausible, tanto para la alta frecuencia en la tasa de mortalidad cardiovascular de Rusia, como para las drásticas fluctuaciones que experimenta durante las últimas décadas. Parecería también que otros factores de riesgo tradicionales identificados en estudios epidemiológicos tendrian poco valor predictivo. El objetivo de este estudio consiste en analizar la relación entre el consumo de alcohol y las tasas de mortalidad por cardiopatía isquémica $(\mathrm{Cl})$ en Rusia. Para ello se utiliza el análisis de series temporales estandarizadas por edad y por sexo de los datos de mortalidad por $\mathrm{Cl}$ masculina y femenina durante el periodo 1980-2005 en relación con el consumo global de alcohol. El análisis muestra como efectivamente el consumo de alcohol se asocia significativamente con las tasas tanto de mortalidad masculina como femenina por $\mathrm{Cl}$. Un aumento de 1 litro en el consumo de alcohol anual se traduciría en un aumento del 3,9\% en la tasa de mortalidad por $\mathrm{Cl}$ en hombres y un 2,7\% en las mujeres. Como conclusión, este estudio proporcionan apoyo indirecto a la hipótesis de que las profundas fluctuaciones en Rusia en la mortalidad por $\mathrm{Cl}$ durante las últimas décadas podría estar relacionado con el alcohol, como lo indica la estrecha relación temporal entre ambos fenómenos.

Palabras clave: cardiopatía isquémica, consumo de alcohol, análisis de series temporales, Rusia. recibido: Abril 2011 aceptado: Septiembre 2011

\section{Abstract}

It has been repeatedly emphasized that alcohol provides the most plausible explanation for both the high rate of cardiovascular mortality rate and its dramatic fluctuations in Russia over recent decades, while other traditional risk factors identified in epidemiological studies have little predictive value. The aim of this study was to examine the relation between alcohol consumption and ischemic heart disease (IHD) mortality rates in Russia. Age-standardized sex-specific male and female IHD mortality data for the period 1980-2005 and data on overall alcohol consumption were analyzed by means of ARIMA time series analysis. The results of the analysis showed that alcohol consumption was significantly associated with both male and female IHD mortality rates: a 1-liter increase in overall alcohol consumption would result in a $3.9 \%$ increase in the male IHD mortality rate and a $2.7 \%$ increase in the female IHD mortality rate. As a conclusion, the results of this study provide indirect support for the hypothesis that the drastic fluctuations in IHD mortality in Russia over recent decades are related to alcohol, as indicated by the close temporal association between number of deaths from IHD and overall alcohol consumption per capita.

Key words: ischemic heart disease, alcohol consumption, ARIMA time series analysis, Russia. 
$\mathrm{T}$ here is convincing evidence that light to moderate alcohol consumption protects against the risk of ischemic heart disease (IHD), while heavy episodic or binge drinking is associated with an increased risk of cardiovascular events (Anderson, 2005; Corrao, Rubbiati, Bagnardi, Zambon, \& Poikolainen, 2000; Marmot, Lucas, Brown, Wassef, \& Giles, 2005). Studies that have looked at pattern of drinking have consistently found that binge drinking an increased risk of IHD death (Bagnardi, Zatonski, Scotti, La Vecchia, \& Corrao, 2008; Mukamal et al., 2003; Puddey, Rakic, Dimmitt, \& Beilin, 1999). A recent metaanalysis of 14 studies containing 4,718 IHD events suggests that heavy irregular drinking occasions (60 g. of pure alcohol per occasion) is significantly associated with incidence of IHD morbidity and mortality compared with regular moderate drinking ( $\mathrm{RR}=1,45 ; \mathrm{Cl}: 1,24-1,7)$ (Roerecke \& Rehm, 2010). This meta-analysis offer evidence that drinking pattern modifies the effects of alcohol intake on the IHD risk. That means that the cardioprotective effect of moderate alcohol consumption disappears when light to moderate drinking is mixed with irregular heavy drinking occasions. Researches have shown that binge drinking produce adverse cardiovascular effects including an atherogenic profile, increased risk of thrombosis and probability of arrhythmia (Britton \& McKee, 2000; McKee \& Britton, 1998).

The link between IHD mortality and population drinking has been analyzed in a number of aggregate-level studies with conflicting results. Hemstrom conducted time-series analyses of per capita consumption and IHD mortality in Western European countries with control for smoking (Hemstrom, 2001). The results suggested an unsystematic distribution of non-significant alcohol effect estimates. In a more recent study using a pooled cross-sectional analysis Gmel and coauthors (2003) showed that in countries with favorable drinking pattern, per capita consumption was negatively associated with IHD mortality whereas a positive link was found in countries with the binge drinking pattern.

It was repeatedly emphasized that alcohol provides the most plausible explanation for both the high rate and the dramatic fluctuation in Russian cardiovascular mortality rate during the last decades, while other traditional risk factors identified in epidemiologic studies had little predictive value (Averina, et al., 2003; Chenet, McKee, Leon, Shkolnikov, \& Vassin, 2001; McKee, Shkolnikov, \& Leon, 2001; Nilssen, et al., 2005; Razvodovsky, 2001). The level of alcohol consumption in Russia is among the highest in the world with an annual sales rate about 10 litres of pure alcohol per capita, while independent estimates show a figure as high as 17 litres (Nemtsov \& Razvodovsky, 2008; Razvodovsky, 2009a).The distinctive trait of Russian drinking culture is the preference for binge drinking of vodka, leading to an increase in deaths from alcohol poisoning and cardiovascular diseases (Nemtsov, 2002; Nemtsov \& Razvodovsky, 2008; Room, 2005; Shkolnikov, McKee, Chervyakov, \& Kyrianov, 2002; Zaridze, et al., 2008). Evidence of a major effect of binge drinking on Russian IHD mortality pattern comes from both aggregate level analyses and studies of individuals (Britton \& McKee, 2000; McKee \& Britton, 1998; Nilssen, et al., 2005; Razvodovsky, 2009b). Close aggregate level association between fatal alcohol poisoning (as a proxy for binge drinking) and IHD mortality rate in Russia has been reported for the period between 1956 and 1998 (Ramstedt, 2009). In the Novosibirsk cohort study was shown that binge drinking (consumption of $160 \mathrm{~g}$. or more of pure alcohol on a typical occasion) seems to be increased risk of death from IHD ( $R R=1,27 ; C l: 0,81-1,99)$ (Malyutina, et al., 2002). Collectively this evidence provides additional support for the hypothesis that unfavorable mixture of higher overall level of alcohol consumption and binge drinking pattern is a major risk factor for IHD mortality in Russia.

In line with these findings, we assume that higher overall level of alcohol consumption and binge drinking pattern in Russia should result in a positive association between alcohol and IHD mortality at the aggregate level. In this study we will test this hypothesis by analyzing Russian's time series data between 1980 and 2005.

\section{Method}

\section{Data}

The data on age-adjusted sex-specific IHD mortality rates per 1000,000 of the population are taken from the Russian State Statistical Committee (Rosstat). The Rosstat's cause of death classification has undergone several changes in recent decades. Until 1988 the cause of death classification was based upon the Soviet nomenclature which had a limited number of causes of death in comparison with the International Classification of Diseases (ICD) system. From 1989-1998 Rosstat used a coding scheme that was based on ICD-9. From 1999 a new coding system based on ICD10 was introduced. Rosstat issued a table of correspondence between its classification system and ICD-9 and ICD-10 and it has been claimed that the Russian system of coding was and is compatible with the ICD. For example Soviet classification 90-95 "lschemic heart disease " corresponds with ICD-9 code E 410-E 414 and with ICD-10 code I20-I25. The overall level of alcohol consumption in Belarus has been estimated using the indirect method (Razvodovsky, 2010).

\section{Statistical analysis}

To examine the relation between changes in the alcohol consumption and IHD mortality across the study period a time-series analysis was performed using the statistical package "Statistica". The dependent variables were the annual IHD mortality and the independent variable was aggregate overall alcohol consumption. Bivariate correlations between the raw data from two time-series can often be spurious due to common sources in the trends and due to autocorrelation (Norstrom \& Skog, 2001). One way to reduce the risk of obtaining a spurious relation between two variables that have common trends is to remove these 
trends by means of a 'differencing' procedure, as expressed in formula:

$$
\nabla x_{t}=x_{t}-x_{t-1}
$$

This means that the annual changes ' $\nabla$ ' in variable ' $X$ ' are analyzed rather than raw data. The process whereby systematic variation within a time series is eliminated before the examination of potential causal relationships is referred to as 'prewhitening'. This is subsequently followed an inspection of the cross-correlation function in order to estimate the association between the two prewhitened time series. It was Box and Jenkins (Box \& Jenkins, 1976) who first proposed this particular method for undertaking a time series analysis and it is commonly referred to as ARIMA (autoregressive integrated moving average) modeling. We used this model specification to estimate the relationship between the time series IHD mortality and alcohol consumption rates in this paper. In line with previous aggregate studies (Norstrom \& Skog, 2001; Razvodovsky, 2009c), we estimated semi-logarithmic models with logged output. The following model was estimated:

$$
\nabla \operatorname{Ln} M_{t}=a+\beta \nabla A_{t}+\nabla N_{t}
$$

where $\nabla$ means that the series is differenced, $M$ is IHD mortality rates, $a$ indicates the possible trend in IHD mortality due to other factors than those included in the model, $A$ is the alcohol consumption, $\beta$ is the estimated regression parameter, and $N$ is the noise term. The percentage increase in IHD mortality rate rates associated with a 1-litre increase in alcohol consumption is given by the expression: $\left(\exp \left(\beta_{1}\right)-1\right)^{*} 100$.

In addition to the estimated effect parameter, the alcohol effect will also be expressed in terms of alcohol attributable fraction (AAF), which is interpreted as the proportion of IHD deaths that is attributable to alcohol. AAF can be calculated from the estimates obtained in ARIMA models according to following formula: $A A F=1-\exp (-b X)$, where $X$ is alcohol consumption for the whole study period and $b$ is the estimated effect parameter.

\section{Results}

The trends in the age-adjusted, sex-specific IHD mortality rates are displayed in Figures 1-2. For both sexes the time series IHD mortality rates fluctuated greatly over the period: decreased substantially (by $6,6 \%$ and $8,8 \%$ for men and women respectively) between 1980 and 1982 , before dropping sharply in the years 1984-1986 (by $24,3 \%$ for males and by $25,9 \%$ for females). From 1988-1989 the series again started on an upward trend, before jumping dramatically during 1991 to 1994. From 1995-1998 there was a fall in the rates before they again began to rise while a decrease in rates has been recorded in the most recent years. Although the sex-specific IHD mortality trends are rather similar over the time series there are substantial differences.
In particular, the rate of IHD mortality increased for both males and females during the transition, but it appear that males were more adversely affected during this period. From 1990 to 1994 the male IHD mortality rate increase by $38,4 \%$, while the female rate increased by $25,9 \%$.

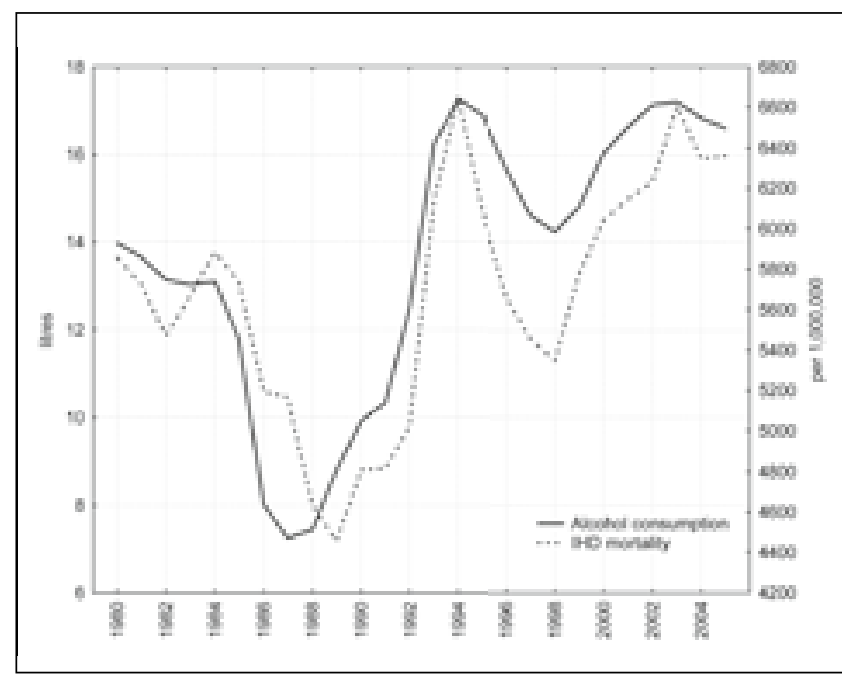

Figure 1. Trends in male IHD mortality rate (right scale) and alcohol consumption per capita (left scale) in Russia between 1980 and 2005.

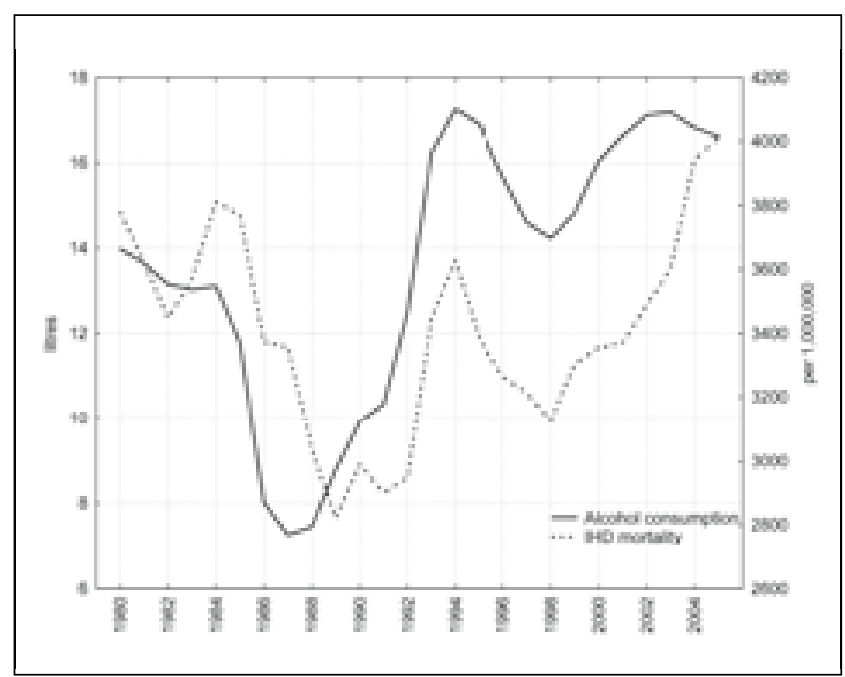

Figure 2. Trends in female IHD mortality rate (right scale) and alcohol consumption per capita (left scale) in Russia between 1980 and 2005.

The graphical evidence suggests that the trends in both alcohol consumption per capita and IHD mortality for males and females seem to follow each other across the time-series (Figures 1-2). As can be seen, there were sharp trends in the time series data across the study period. These trends were removed by means of a first-order differencing procedure. After prewhitening the cross-correlations between alcohol consumption and the IHD mortality time series were inspected. This indicated that there was a statistically significant cross-correlation between alcohol consumption 
and IHD mortality for males and females at lag 0 (Table 1). The specification of the bivariate ARIMA model and outcome of the analyses are presented in Table 2. The estimated effects of overall alcohol consumption on the IHD mortality rate are clearly statistically significant for both sexes. The analysis suggests that a 1 liter increase in overall alcohol consumption would result in a $3.9 \%$ increase in the male IHD mortality rate and in $2.7 \%$ increase in female IHD mortality rate.

Table 1. The results of cross-correlation analysis between prewhitened time series. Effects of alcohol consumption per capita on IHD mortality rates.

\begin{tabular}{ccccc}
\hline & \multicolumn{2}{c}{ Mortality males } & \multicolumn{2}{c}{ Mortality females } \\
\hline Lag & $r$ & SE & $r$ & SE \\
\hline-3 & -0.052 & 0.213 & 0.131 & 0.213 \\
-2 & 0.091 & 0.209 & 0.146 & 0.209 \\
-1 & 0.390 & 0.204 & 0.394 & 0.204 \\
0 & 0.742 & 0.200 & 0.597 & 0.200 \\
1 & 0.282 & 0.204 & 0.087 & 0.204 \\
2 & -0.090 & 0.209 & -0.246 & 0.209 \\
3 & -0.231 & 0.213 & -0.280 & 0.213 \\
\hline
\end{tabular}

Table 2. Estimated effects (bivariate ARIMA model) of overall alcohol consumption on IHD mortality rates

\begin{tabular}{lccc}
\hline & \multicolumn{3}{c}{ Alcohol consumption } \\
\hline Parameter & Model & Estim. & $\mathrm{p}$ \\
\hline IHD mortality males & $1,1,0^{*}$ & 0,039 & 0,05 \\
IHD mortality females & $1,1,0$ & 0,027 & 0,05 \\
\hline
\end{tabular}

*The general form of non-seasonal ARIMA model is $(p, d, q)$, where $p$ - the order of the autoregressive parameter, $d$ - the order of differencing, and $q$ - the order of the moving average parameter. $Q$ test for residuals are satisfactory in all models.

A feasible way of estimation the impact of the alcohol factor on IHD mortality is to compute the alcohol attributable fraction on the basis of aggregate findings. Such a calculation yields an AAF equal to $41 \%$ for males and $31 \%$ for females.

\section{Discussion}

There is evidence that the IHD mortality trends in Russia influenced by the four major factors: the longstanding mortality crisis that began in the USSR in the 1960s, the brief Andropov's anti-alcohol campaign in the early 1980s, Gorbachev's anti-alcohol campaign 198588 and severe socioeconomic crisis imposed by rapid societal transformation in the early 1990s. A fairly close aggregate-level match between alcohol consumption and IHD mortality during the Andropov's and Gorbachev's antialcohol campaigns may be use as evidence for the hypothesis suggesting that alcohol is responsible for a substantial number of IHD deaths in Russia.
On the other hand, several researchers argue that alcohol unlikely provide the universal explanation for the mortality fluctuations during 1980s in Russia as the proportion of heavy binge drinkers in women is negligible, but the temporal changes in deaths rates were similar in men and women (Wasserman, Varnik, \& Eklund, 1994). They believe that the decrease in mortality rates in Russia in the mid-1980s could have been related to the political and social liberalization during the period known as "perestroika", which gave rise to social optimism and new hope. However, findings from neighboring Belarus based on autopsy reports from the Bureau of Forensic Medicine suggest that the number of BAC-positive cardiovascular deaths shrank by $33,6 \%$, while the number of BAC-negative deaths increased by $14,4 \%$ during Gorbachev's perestroika (Razvodovsky, 2001).

While some experts have underlined the importance of binge drinking as the main reason for the IHD mortality crisis in Russia in the 1990s, other has called attention to the effect of the psychosocial distress of economic and political reforms (Gavrilova, Semyonova, Evdokushkina, \& Gavrilov, 2000; Leon \& Shkolnikov, 1998;). The collapse of the USSR in 1991 and growth of consumer prices in 1992 were followed by declining of living standards majority of population (Brainerd \& Cutler, 2005; Stuckler, King, \& McKee, 2009). The impact of acute socioeconomic transition has been exacerbated by a lack of social cohesion, erosion of social capital, loss of control over life and rising income inequality (Andreeva, Ermakov, \& Brenner, 2008). That might undermine the health of the population.

Psychosocial distress is increasingly recognized as a risk factor for IHD morbidity and mortality (Marmot, 1988). Several retrospective studies claim to show that acute stressors such as natural disasters and terrorist activities can trigger acute myocardial infarction in sufferers of IHD (Hiroyasu, et al., 2002; Kopp, Skrabski, Szanto, \& Siegrist, 2006). Chronic stress such as job strain has also been shown to have a strong association with IHD events (Greenwood, Muir, Packham, \& Madeley, 1996). There are several potential pathways for the effect of psychosocial distress on IHD. Chronic psychosocial distress may cause pathophysiological abnormality, including hypothalamic pituitary axis activation, adrenalin hyperactivity, dyslipidemia, increased plateled aggregation, raised fibrinogen level and the progression of carotid atherosclerosis, while acute stress increase heart rate, blood pressure and myocardial oxygen demand (Hiroyasu, et al., 2002; Kivimaki, et al., 2002).

One of the most interesting features of IHD mortality crisis in Russia in the early 1990s is the gender difference in spite of the fact that men and women share the same socio-economic circumstances. It seems that males were most vulnerable to the stressful experience resulting from abrupt socioeconomic changes, political instability, unemployment and impoverishment. This disproportionately affects the working age male population because their work and family roles rendered them more vulnerable to socioeconomic disruption (Gavrilova, et al., 2000). This evidence is consistent with the findings from the crosssectional population survey, which explores the contribution 
of socioeconomic, work related, psychosocial, and behavioral variables in variations of middle aged male and female cardiovascular mortality across sub-regions in Hungary (Kopp, et al., 2006). It was reported that low social support at work, and low control at work account for a large part of variation in male premature cardiovascular mortality rates. Moreover, low social support from friends, depression, anomie, hostility, alcohol misuse and cigarette smoking also explain a considerable part of variations of premature cardiovascular mortality differences. These findings suggest that the Russian IHD mortality crisis is most likely to have been precipitated by the psychosocial distress imposed by rapid societal transformation. Nevertheless, the experience of some transitional Central and Eastern European countries does not necessarily imply that the implementation of rapid economic reforms is accompanied by growing mortality. For example, a rapid decline in IHD mortality in Poland was reported between 1991 and 1994 (Zatonski \& Willet, 2005). In Hungary, increase in IHD mortality was observed between 1970 and the early 1990s of 35\%, but thereafter, a decrease of $2 \%$ year was noted (Ginter, 1995; Kesteloot, Sans, \& Kromhout, 2006).

Several studies have suggested that men in Russia, as a result of traditional masculine norms, are more prone to respond to stressful situations with maladaptive behavior such as increased alcohol consumption, while women have a more adaptive stress response. Based on interviews conducted with a stratified random sample of 1190 Moscovites Jukkala end coauthors (2008) concluded that experiencing several kinds of economic problems is positively related to the risk of binge drinking among men. In contrast, women seemed less likely to binge drink when experiencing manifold economic problems. Cockerham et al. (2006) found that in Russia psychological distress promote frequent drinking among men, but not among women, even though women reported significantly more distress. So, psychosocial distress may be indirectly associated with cardiovascular mortality through unhealthy lifestyle such as binge drinking.

The outcomes from Novosibirsk study have important implications for understanding the role of binge drinking in the Russian mortality crisis during 1990s (Malyutina, et al., 2002). It was highlighted that the rates of frequent heavy drinking increased from 3,5\% in 1985/86-1988/89, to $8.4 \%$ in 1994/95; the corresponding attributable risk fraction for cardiovascular deaths would be $7 \%$ in the 1980 s and $16 \%$ in the 1990s. These findings, as well as the results of present study, highlighting close aggregate level association between alcohol consumption and IHD mortality rates strongly support an alcohol related hypothesis and suggest that rather that playing major causal role, psychosocial distress may represent a confounding factor. It seems plausible that the psychosocial distress was the main cause of increased demand for alcohol at this time. This demand was met by factors that increased supply following the repeal of state alcohol monopoly in 1992 (Nemtsov \& Razvodovsky, 2008).

There are several potential factors behind the decrease in alcohol consumption and IHD mortality rates between 1994 and 1998. They include better regulation of the alcohol market that may have resulted in a relative increase in prices for alcohol compared to those for food products (Nemtsov \& Razvodovsky, 2008). Another possible factor in the decrease in alcohol consumption was impoverishment and decrease in the purchasing capacity of the population due to unpaid or delayed salaries (Nemtsov, 2002). On the other hand, the decreases in IHD mortality in 1994-98 coincided with improvement in the economic situation, while the increases since 1998 correlate with financial crisis and worsening economic situation (Nemtsov \& Razvodovsky, 2008).

Before concluding, several potential limitations of this study must be mentioned. In particular, there was the risk of omitted variable bias in this work. It can be assumed that psychosocial distress and alcohol consumption effects on IHD mortality are spurious indicators of the impact of other powerful risk factors, i.e. smoking. Smoking is associated with higher risk of IHD mortality (Kuulasmaa, et al., 2000). The high prevalence of smoking among Russian men (about $60 \%$ ) probably explains a fact of the high male IHD mortality rate compared with the female mortality rate (Bobak, Gilmore, Mckee, \& Marmot, 2006). However, use of tobacco products was relatively stable during 1970s-1980s and has fallen substantially in Russia over the 1990s, suggesting that IHD mortality crisis is not a result of a long-term response to smoking trends (Nemtsov \& Razvodovsky, 2008). Further, in a recent time series analysis it was highlighted that smoking as indicated from sales data did not have a significant impact on IHD in Russia (Ramstedt, 2009).

In conclusion, the outcomes of this study provide indirect support for the hypothesis that the profound fluctuations in IHD mortality seen in Russia during recent decades may be related to alcohol, as indicated by a close temporal association between number of deaths from IHD and overall alcohol consumption per capita. The findings from the present study have important implications as regards cardiovascular mortality prevention indicating that a restrictive alcohol policy can be considered as an effective measure of prevention in countries where higher rate of alcohol consumption and detrimental drinking pattern.

\section{Conflict of interests}

None declared.

\section{References}

Anderson, P. (2005). Alcohol and coronary heart disease. Addiciones, 7, 3-10.

Andreeva, E., Ermakov, D., \& Brenner H. (2008). The socioeconomic etyology of suicide mortality in Russia. International Journal of Environment and Sustainable Development, 7, 21-48.

Averina, M., Nilssen, 0., Brenn, T., Brox, J., Kalinin, A. G., \& Arkhipovsky, V. L. (2003). High cardiovascular mortality in Russia cannot be 
explained by the classical risk factors. The Archangelsk Study 2000. European Journal of Epidemiology, 18, 871-8.

Bagnardi, V., Zatonski, W., Scotti L., La Vecchia C., \& Corrao G. (2008). Does drinking pattern modify the effect of alcohol on the risk of coronary heart disease? Evidence from a meta-analysis. Journal Epidemiology Community Health, 62, 615-619.

Bobak, M., Gilmore, A., Mckee, M., \& Marmot, M. (2006). Changes in smoking prevalence in Russia, 1996-2004. Tobacco Control, 15, 131-135.

Box, G. E. P., \& Jenkins, G. M. (1976). Time Series Analysis: forecasting and control. London. Holden-Day Inc.

Brainerd, E., \& Cutler, D. M. (2005). Autopsy on an Empire: Understanding mortality in Russia and the former Soviet Union. Journal of Economic Perspective, 19(1), 107-130.

Britton, A., \& McKee, M. (2000). The relation between alcohol and cardiovascular disease in Eastern Europe. Explaining the paradox. Journal of Epidemiology and Community Health, 54(5), 328-332.

Chenet, L., McKee, M., Leon, D., Shkolnikov, V., \& Vassin S. (2001). Alcohol and cardiovascular mortality in Moscow: new evidence of a causal association. Journal of Epidemiology and Community Health, 52, 772-74.

Cockerham, W. C., Hinote, B. P., \& Abbott, P. (2006). Psychological distress, gender, and health lifestyles in Belarus, Kazakhstan, Russia, and Ukraine. Social Science \& Medicine, 63, 2381-2394.

Corrao, G., Rubbiati, L., Bagnardi, V., Zambon, A., \& Poikolainen, K. (2000). Alcohol and coronary heart disease: a meta-analysis. Addiction, 95, 1505-23.

Gavrilova, N. S., Semyonova, V. G., Evdokushkina, G. N., \& Gavrilov, L. A. (2000). The response of violent mortality to economic crisis in Russia. Population Research and Policy Review, 9, 397-419.

Ginter, E. (1995). Cardiovascular risk factors in the former communist countries. Analysis of 40 European MONICA populations. European Journal of Epidemiology, 11, 199-205.

Gmel, G., Rehm, J., \& Frick, U. (2003). Trinkmuster, Pro-Kopf-Konsum von Alkohol und koronare Mortalitat. Sucht, 49, 95-104.

Greenwood, D. C., Muir, K. R., Packham C. J., \& Madeley, R. J. (1996). Coronary heart disease: a review of the role of psychosocial stress and social support. Journal of Public Health Medicine, 18(2), 221231.

Hemstrom, 0. (2001). Per capita alcohol consumption and ischemic heart disease mortality, Addiction, 96(Supplement 1), 93-112.

Hiroyasu, I., Chigusa, D., Yamamoto, A., Toyoshima, H., Tanabe, N., \& Kikuchi, S. (2002). Perceived mental stress and mortality from cardiovascular disease among Japanese men and women. Circulation, 106, 1229-1234.

Kesteloot, H., Sans, S., \& Kromhout, D. (2006). Dynamics of cardiovascular and all-cause mortality in Western and Eastern Europe between 1970 and 2000. European Heart Journal, 27, 107113.

Kivimaki, M., Leino-Arjas, P., Luukkonen, R., Riihimaki, H., Vahtera, J., \& Kirjonen, J. (2002). Work stress and risk of cardiovascular mortality: prospective cohort study of industrial employees. British Medical Journal, 325, 857-864.

Kopp, M., Skrabski, A., Szanto, Z., \& Siegrist, J. (2006). Psychosocial determinants of premature cardiovascular mortality differences within Hungary. Journal of Epidemiology and Community Health, $60,782-788$

Kuulasmaa, K., Tunstall-Pedoe, H., Dobson, A., Fortmann, S., Sans, S., Tolonen H., Evans A., Ferrario, M., \& Tuomilehto, J. (2000). Estimation of contribution of changes in classic risk factors to trends in coronary-event rates across the WHO MONICA Project populations. Lancet, 355, 675-87.

Leon, D. A., \& Shkolnikov, V. M. (2005). Social stress and the Russian mortality crisis. Journal of American Medical Association, 279, 790-91.

Lucas, D. L., Brown, R. A., Wassef, M., \& Giles, T. D. (2005). Alcohol and the cardiovascular system. Journal of the American College of Cardiology, 45, 1916-1924.

Malyutina, S., Bobak, M., Kurilovitch, S., Gafarov, V., Simonova, G., Nikitin, Y., \& Marmot M. (2002). Relation between heavy and binge drinking and all-cause and cardiovascular mortality in Novosibirsk, Russia: a prospective cohort study. Lancet, 360, 1448-54.

Marmot, M. (1988). Psychosocial factors and cardiovascular disease: epidemiological approaches. European Heart Journal, 6, 690-697.

Marmot, M. (2001). Commentary: reflection on alcohol and coronary heart disease. International Journal of Epidemiology, 30, 729-34.

McKee, M., \& Britton, A. (1998). The positive relationship between alcohol and heart disease in Eastern Europe: potential physiological mechanisms. Journal of the Royal Society of Medicine, 91, 402-407.

McKee, M., Shkolnikov, V., \& Leon, D. A. (2001). Alcohol is implicated in the fluctuations in cardiovascular disease in Russia since the 1980s. Annals of Epidemiology, 1, 11-6.

Mukamal, K. J., Conigrave, K. M., Mittleman, M. A., Camargo, C. A., Stampfer, M. J., Willett, W. C., \& Rimm, E. B. (2003). Roles of drinking pattern and type of alcohol consumed in coronary heart disease in men. The New England Journal of Medicine, 348(2), 109-18.

Nemtsov, A. V., \& Razvodovsky, Y. E. (2008). Alcohol situation in Russia, 1980-2005. Social and Clinical Psychiatry, 2, 52-60.

Nemtsov, A. V. (2002). Alcohol-related human losses in Russia in the 1980s and 1990s. Addiction, 97, 1413-1425.

Nilssen, O., Averina, M., Brenn, T., Drox, J., Kalinin, A., \& Archipovski, V. (2005). Alcohol consumption and its relation to risk factors for cardiovascular disease in the north-west of Russia: the Archangelsk study. International Journal of Epidemiology, 34, 781-788.

Norstrom, T., \& Skog, O. J. (2001). Alcohol and mortality: methodological and analytical issue in aggregate analysis. Addiction, 96, 5-17.

Puddey, I. B., Rakic, V., Dimmitt, S. B., \& Beilin, L. J. (1999). Influence of pattern of drinking on cardiovascular disease and cardiovascular risk factors - a review. Addiction, 94, 649-663.

Ramstedt, M. (2009). Fluctuations in male ischemic heart disease mortality in Russia 1959-1998: Assessing the importance of alcohol. Drug and Alcohol Review, 28, 390-395.

Razvodovsky, Y. E. (2001). Alcohol and cardiovascular mortality: epidemiological aspect. Alcologia, 13, 107-113.

Razvodovsky, Y. E. (2009a). Alcohol consumption and mortality in Russia and Belarus. Medical News, 16, 41-46.

Razvodovsky, Y. E. (2009b). Aggregate level beverage specific effect of a sale on myocardial infarction mortality rate. Adicciones, 21, 229-238.

Razvodovsky, Y. E. (2009c). Alcohol poisoning and cardiovascular mortality in Russia 1956-2005. Alcoholism, 45, 27-42.

Razvodovsky, Y. E. (2010). Unrecorded alcohol consumption: quantitative methods of estimation. Alcoholism, 46, 15-24.

Roerecke, M., \& Rehm, J. (2010). Irregular heavy drinking occasions and risk of ischemic heart disease: a systematic review and metaanalysis. American Journal of Epidemiology, 171, 633-644. 
Room, R. (2005). Commentary: pattern of drinking and the Russian heart. International Journal of Epidemiology, 34, 788-90.

Shkolnikov, V. M., McKee, M., Chervyakov, V. V., \& Kyrianov, N. A. (2002). Is the link between alcohol and cardiovascular death among young Russian men attributable to misclassification of acute alcohol intoxication? Evidence from the city of Izhevsk. Journal of Epidemiology \& Community Health, 56, 171-175.

Stuckler, D., King, L., \& McKee, M. (2009). Mass privatization and the post-communist mortality crisis: a cross-national analysis. Lancet, 373, 399-407.

Wasserman, D., Varnik, A., \& Eklund, G. (1994). Male suicides and alcohol consumption in the former USSR. Acta Psychiatrica Scandinavica, 89, 306-313.
Yukkala, T., Makinen, I. H., Kislitsyna, O., \& Ferlander, S. (2008). Economic strain, social relations, gender, and binge drinking in Moscow. Social Science \& Medicine, 66(3), 663-74.

Zaridze, D., Maximovitch, D., Lazarev, A., Igitov, V., Boroda, A. Boreham, J., Boyle, P., Peto, R., \& Boffetta, P. (2008). Alcohol poisoning is a main determinant of recent mortality trends in Russia: evidence from a detailed analysis of mortality statistics and autopsies. International Journal of Epidemiology, 38, 143-153.

Zatonski, W. A., \& Willet, W. (2005). Changes in dietary fat and declining coronary heart disease in Poland: population based study. British Medical Journal, 331, 187-189. 
